\title{
Contactless Palmprint Recognition Based on the KLT Feature Points
}

\author{
Min-Ki Kim ${ }^{\dagger}$
}

\begin{abstract}
An effective solution to the variation on scale and rotation is required to recognize contactless palmprint. In this study, we firstly minimize the variation by extracting a region of interest(ROI) according to the size and orientation of hand and normalizing the ROI. This paper proposes a contactless palmprint recognition method based on KLT(Kanade-Lukas-Tomasi) feature points. To detect corresponding feature points, texture in local regions around KLT feature points are compared. Then, we recognize palmprint by measuring the similarity among displacement vectors which represent the size and direction of displacement of each pair of corresponding feature points. An experimental results using CASIA public database show that the proposed method is effective in contactless palmprint recognition. Especially, we can get the performance of exceeding $99 \%$ correct identification rate using multiple Gabor filters.
\end{abstract}

Keywords : Contactless Palmprint Recognition, KLT Feature Point, Gabor Filters

\section{$\mathrm{KLT}$ 특징점에 기반한 비접촉 장문인식}

\author{
김 민 기 ${ }^{\dagger}$
}

\section{요 약}

\begin{abstract}
비접촉 장문을 인식하기 위해서는 영상의 크기 및 회전 변형을 효과적으로 해결해야 한다. 본 연구에서는 손의 크기와 방향에 따라 관 심영역(ROI)을 추출한 후 정규화하여 일차적으로 이러한 변형을 최소화하였다. 본 논문에서는 KLT(Kanade-Lukas-Tomasi) 특징점에 기반 한 비접촉 장문인식 방법을 제안한다. 대응되는 $\mathrm{KLT}$ 특징점 주위의 국소영역에 대한 텍스처를 비교하여 대응되는 특징점을 검출한 후, 특 징점 쌍의 변위 크기와 방향을 나타내는 변위벡터들 간의 유사도를 비교하여 장문을 인식한다. CASIA 공개 데이터베이스를 이용한 실험 결과 제안된 방법이 비접촉 장문인식에 효과적임을 확인할 수 있었다. 특히 다중 가버 필터를 이용하였을 때 $99 \%$ 를 상회하는 정인식률을 얻을 수 있었다.
\end{abstract}

키워드 : 비접촉 장문인식, $\mathrm{KLT}$ 특징점, 가버 필터

\section{1. 서 론}

사람의 손에는 지문(finger print), 장문(palmprint), 손가 락 관절문(finger-knuckle-print) 등 개인을 식별할 수 있는 다양한 생체정보가 존재한다. 손바닥에 나타나는 손금( $\mathrm{palm}^{-}$ line)들로 형성되는 장문은 지문에 비하여 닳아 없어지지 않 아 견고성이 높고, 식별 정보가 넓게 분포되어있어 부분적 인 변형에도 강인한 특성을 가지고 있다. 장문은 저해상도 영상에서도 손금에 대한 변별이 가능하기 때문에 홍채나 지 문을 이용하는 생체인식 시스템에 비하여 저렴한 영상 획득

\footnotetext{
† 종신회원 : 경상대학교 컴퓨터과학과, 공학연구원(ERI)

Manuscript Received: June 27, 2014

First Revision: September 3, 2014

Accepted : September 3, 2014

* Corresponding Author:Min-Ki Kim(mkkim@gnu.ac.kr)
}

장비의 사용이 가능하다. 또한 지문과는 달리 영상 획득 과 정에서 사용자가 느끼는 정서적 거부감이 적은 장점이 있다 $[1,2]$.

장문인식을 위해서는 손바닥 영상(palm image)의 획득, 전처리, 관심영역 추출, 특징 추출, 정합(matching)이라는 과 정을 거치게 되는데, 이 중에서 장문의 특징을 추출하고 기 술하는 부분이 장문인식 연구의 핵심이 된다. 장문은 영상 의 획득 방법에 따라 접촉식과 비접촉, 영상의 정밀도에 따 라 고해상도와 저해상도로 나누어볼 수 있다. 접촉식은 평 평한 판 위에 손을 올려놓거나 유도 막대(peg)에 손가락을 끼운 상태에서 영상을 획득하므로, 크기 및 회전 변형이 적 어 인식이 용이하나 사용자에게 불편함을 줄 뿐만 아니라 여러 사람이 이용함으로써 위생상의 문제를 유발시킬 수 있 다[3]. 이에 비하여 비접촉식 방식은 이러한 문제들을 해소 할 수 있지만 획득된 영상의 크기 및 회전 변형에 의하여 
장문인식을 더욱 어렵게 만든다. 초기의 장문인식 연구는 접촉식 방식으로 획득한 영상을 대상으로 시작되었다. $400 \mathrm{dpi}$ 이상의 고해상도 영상은 주로 범죄수사(forensic)의 목적으로 연구되었고, 저해상도 영상은 상업적 목적으로 연구되었다[4]. 최근의 연구들은 대부분 저해상도 영상을 대상으로 하고 있으며, 비접촉 장문 영상에 대한 관심이 높아지고 있다.

기존의 장문인식에 대한 연구들은 영상의 전체적인 명도 값 분포를 특징으로 기술하는 부공간(subspace) 기반 방식 $[5,6]$, 장문의 패턴을 구성하는 주획(principal line)과 주름 (wrinkle)의 위치와 형태를 특징으로 하는 라인 기반 방식 [7-9], 국소영역으로부터 손금의 방향을 나타내는 방향코드 (orientation code) 기반 방식 등으로 구분해볼 수 있다. 이 들 중 국소영역으로부터 손금의 방향을 나타내는 방향코드 방식[10-15]이 다른 방식에 비하여 장문인식에 효과적인 것 으로 나타났다. 국소영역에서 방향코드를 안정적으로 추출 하기 위하여 가버(Gabor) 필터[10, 11], 방향 템플리트 (directional template)[12], 수정된 유한라돈변환(MFRAT, modified finite radon transform)[13, 14] 등이 사용되었다. MFRAT는 방향성 템플리트에 비하여 방향코드의 성능을 개선하였으며, CompCode[10]는 가버 필터를 적용하여 손금 정보를 강조시켜 방향코드를 생성하였다. Sun 외[15]는 비 접촉 장문 영상에서 발생하는 조명 변화에 강인한 OLOF(Orthogonal Line Orientation Feature)를 제안하였다. 최근에는 방향코드의 대안으로 텍스처 기반 방법이 비접촉 장문을 인식하기 위한 새로운 방법으로 대두되고 있다. 국 소영역의 텍스처를 기술하기 위하여 Michael 외[16]는 그레 이디언트 정보에 기반한 국부이진패턴(LBP, Local Binary Pattern)을 이용하였고, Morales 외[17]는 SIFT(Scale Invariant Feature Transform) 특징점을 기반으로 국소영역 의 텍스처를 기술하였다.

본 논문에서는 안정적인 특징점 추출이 가능하면서 SIFT 특징점에 비해 신속하게 검출이 가능한 KLT(Kanade- LukasTomasi) 특징점을 기반으로 텍스처를 기술하고, 변위벡터를 도입하여 손가락의 움직임에 의해 발생하는 국부적인 변형 에 강인한 비접촉 장문인식 방법을 제안한다. 질의영상에서 추출한 특징점 $p_{1}$ 이 데이터베이스에 저장된 참조영상에서 추출된 특징점 $p_{2}$ 에 대응된다고 할 때, 변위벡터는 대응되 는 특징점 $p_{1}$ 과 $p_{2}$ 간의 이동 변위를 나타내는 벡터 $\overrightarrow{p_{1} p_{2}}$ 로 정의된다. 만약 두 개의 장문영상이 동일인으로부터 획득된 것이라면 이 두 영상 간의 변위벡터들은 유사한 크기와 방 향을 나타낼 것이고, 그렇지 않다면 변위벡터들은 상이한 크기와 방향을 갖게 될 것이다. 따라서 변위벡터 간의 유사 도 정합을 통해 장문을 인식할 수 있다.

본 논문의 구성은 다음과 같다. 1절 서론에 이어, 2절에서 는 비접촉식으로 획득한 손 영상에서 장문이 나타나는 관심 영역(ROI, Region Of Interest)을 추출하는 방법을 기술하고, 3절에서는 $\mathrm{KLT}$ 특징점 추출 및 변위벡터 정합에 대하여 설
명한다. 본 논문에서 제안하는 시스템은 일대다 비교를 통 해 장문을 식별(identification)하는 시스템으로 변위벡터 정 합에 의한 유사도 순서에 따라 인식 후보를 결정하게 된다. 4절에서는 공개 데이터베이스를 이용한 실험을 통하여 제안 된 방법의 타당성을 검증하고, 5절에서 결론을 맺는다.

\section{2. 관심영역 추출}

비접촉식 방식으로 획득한 영상은 손의 크기는 물론 손의 방향이 조금씩 다르게 나타나므로, 손 영상에서 장문이 나 타나는 관심영역 $(\mathrm{ROI})$ 을 일관성 있게 추출하는 것이 매우 중요하다. 일관성이 있다는 것은 동일인에게서 획득한 손 영상들로부터 추출한 $\mathrm{ROI}$ 가 가급적 동일한 영역을 나타냄 을 의미한다. ROI를 추출하는 방법은 참조점 방식과 내접 방식으로 구분된다. 참조점 방식[18]은 손가락 사이의 분기 점(valley point)을 기반으로 손바닥의 중심을 찾는 방법이 고, 내접 방식[19]은 손바닥 영역에서 가장 크게 내접하는 사각형이나 원을 찾아 그 중심을 손바닥의 중심으로 정하는 방법이다. 본 연구에서는 두 가지 방식을 모두 구현하여 실 험한 결과 내접 방식은 손목 부위에 나타나는 잡영에 취약 하였으나, 손가락 사이의 분기점은 안정적으로 추출이 가능 하여 참조점 방식으로 $\mathrm{ROI}$ 를 추출하였다. 비접촉 방식으로 획득한 영상에서 손과 카메라와의 거리에 따라 손의 크기가 달라질 수 있으므로 ROI도 이에 비례하여 그 크기를 설정 할 필요가 있다. 본 연구에서는 손의 크기를 검지와 중지 사이의 분기점 $P_{1}$ 과 약지와 소지 사이의 분기점 $P_{3}$ 간의 거리로 추정하였다. 왜냐하면 이 두 분기점은 안정적으로 추출이 가능하고 손가락을 자연스럽게 벌렸을 때 거리가 크 게 변하지 않기 때문이다. ROI를 추출하는 알고리즘은 다음 과 같이 요약된다.

(1) 손 영상을 이진영상으로 변환한 후 윤곽선을 검출한다 (Fig. 1A).

(2) 윤곽선상의 굴곡을 계산하여 손가락 분기점을 추출한다 (Fig. 1C).

(3) 검지와 중지 사이의 분기점 $P_{1}$ 과 약지와 소지 사이의 분 기점 $P_{3}$ 을 연결하는 선분 $\overline{P_{1} P_{3}}$ 의 중점에서 손바닥 쪽으 로 수선을 그어 선분 $\overline{P_{1} P_{3}}$ 길이 $l$ 의 0.8 배가 되는 지점 을 $P_{c}$ 로 설정한다(Fig. $1 \mathrm{D}$ ).

(4) $P_{c}$ 를 지나는 선분 $\overline{P_{1} P_{3}}$ 와 평행한 직선을 그어, 이 직선 과 윤곽선이 만나는 점을 $E_{1}, E_{2}$ 라고 할 때, $P_{c}$ 를 선분 $\overline{E_{1} E_{2}}$ 의 중점이 되도록 이동시킨 후 $P_{c}$ 를 중심으로 한 변의 길이가 선분 $\overline{P_{1} P_{3}}$ 의 1.2 배가 되는 정사각형을 $\mathrm{ROI}$ 로 설정한다 $(\mathrm{Fig} .1 \mathrm{E})$.

Fig. 1은 제안된 ROI 추출 과정을 예시한 것으로, 검출된 


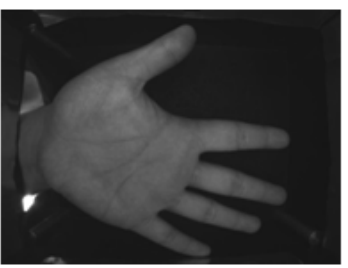

(A)

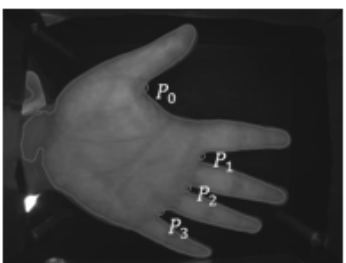

(C)

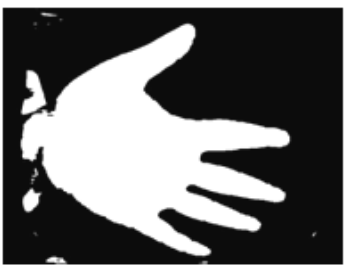

(B)

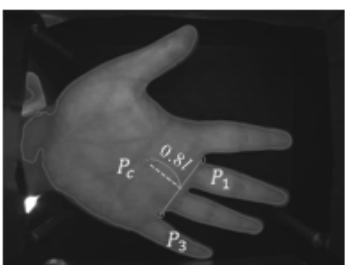

(D)

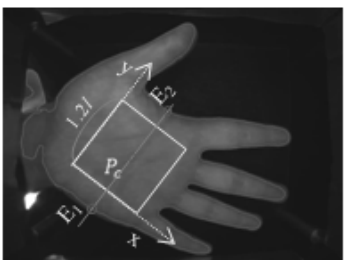

(E)

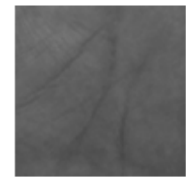

(F)
Fig. 1. ROl localization: (A) input image, (B) binarized image, (C) hand contour and valley points, (D) center point of a palm, (E) detected ROI, (F) normalized ROI

ROI는 Fig. $1 \mathrm{~F}$ 에 나타난 바와 같이 $x$ 축이 수평이 되도록 회전시킨 후 $150 \times 150$ 크기로 정규화한다. 이와 같이 회전 및 크기 정규화를 수행함으로써 비접촉식 영상에서 나타나 는 크기 및 회전 변형을 최소화할 수 있다.

\section{3. 특징점 추출 및 정합}

\section{1 $\mathrm{KLT}$ 특징점 추출}

장문 영상 중 일부는 명암 대비가 낮고 주름이 명확하게 나타나지 않아 효과적으로 KLT 특징점을 검출하기 위해서 는 영상 개선이 필요하다. 장문에 나타나는 주획과 주름의 방향을 강조하기 위하여 equation (1)에 제시된 가버 필터를 사용하였다. 장문에는 여러 방향의 주획과 주름이 존재하므 로, 여러 방향의 가버 필터를 사용하면 장문의 나타나는 손 금의 방향을 효과적으로 강조할 수 있다[12]. 사인(sine) 파 형의 주파수 $(u)$ 는 0.1 , 표준편차 $(\sigma)$ 는 2.0 을 사용하였다.

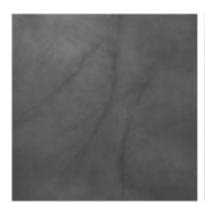

(A)

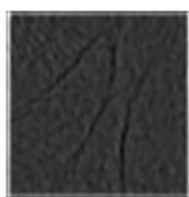

(B)

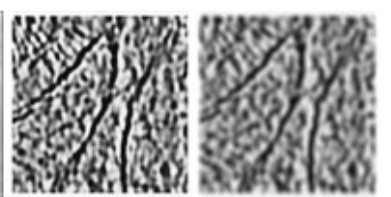

(C)

(D)

Fig. 2. (A) ROl image, (B) Gabor filtering, (C) equalization, (D) mean filtering

$$
\begin{aligned}
G(x, y, \theta, u, \sigma)= & \frac{1}{2 \pi \sigma^{2}} \exp \left\{-\frac{x^{2}+y^{2}}{2 \sigma^{2}}\right\} \\
& \times \exp \{2 \pi i(u x \cos \theta+u y \sin \theta)\}
\end{aligned}
$$

Fig. 2는 추출된 ROI 영상으로부터 $\mathrm{KLT}$ 특징점을 추출 하기 위한 전처리 과정을 보여주고 있다. Fig. $2 \mathrm{~B}$ 는 가버 필 터링 후 직류성분을 제거한 결과이다. 직류성분을 제거하면 영상이 균일한 밝기를 나타내는 이점이 있으나, 영상의 명 도 대비가 낮아지기 때문에 직류 성분을 제거한 후 히스토 그램 평활화를 수행하였다. 끝으로 고주파 잡영을 제거하기 위하여 $5 \times 5$ 평균 필터를 적용하였다.

전처리를 통해 개선된 영상으로부터 equation (2)에 제시 된 $2 \times 2$ 행렬 $M$ 의 고윳값을 이용하여 $\mathrm{KLT}$ 특징점을 검출 한다. 행렬 $M$ 의 요소들은 $N \times N$ 크기의 블록에서 소벨 (Sobel) 연산자를 이용한 미분값으로 계산된다. $D_{x}$ 와 $D_{y}$ 는 각각 $x$ 방향과 $y$ 방향의 1 차 미분을 나타내며, $D_{x y}$ 는 혼합된 2 차 편미분을 나타낸다. $N$ 은 홀수이고, 블록의 크기가 작으 면 잡영에 민감하고 크면 보다 많은 처리시간이 소요된다. 본 연구에서는 $5 \times 5$ 블록을 사용하였다.

$$
M=\left[\begin{array}{ll}
\sum D_{x}^{2} & \sum D_{x y} \\
\sum D_{x y} & \sum D_{y}^{2}
\end{array}\right]
$$

행렬 $M$ 의 고윳값 $\lambda_{1}, \lambda_{2}$ 는 equation (3)과 같이 정의된 다. 여기서 $a$ 와 $c$ 는 행렬 $M$ 의 대각 요소인 $\sum D_{x}^{2}$ 와 $\sum D_{y}^{2}$ 이고, $b$ 는 $\sum D_{x y}$ 이다. 블록 내 명도 값 분포가 균일하다면 두 고윳값은 모두 작게 나타나고, 블록 내에 한쪽 방향의 텍스처 패턴만이 존재하면 두 고윳값은 한 개만 큰 값을 갖 게 된다. 두 개의 고윳값이 모두 큰 경우는 코너점 또는 추 적이 용이한 특징점을 나타낸다[20].

$$
\lambda_{1,2}=\frac{a+c \pm \sqrt{(a-c)^{2}-4 b^{2}}}{2}
$$

두 고유값 중 최솟값이 미리 설정된 임계값보다 크면 해 당 블록의 중심점을 특징점으로 설정한다. equation (4)에서 $\lambda_{m}$ 은 영상 내의 $\min \left(\lambda_{1}, \lambda_{2}\right)$ 중 최댓값을 나타내며, $q$ 는 추출되는 특징점의 질을 제어하는 상수로, 본 연구에서는 0.1 로 설정하였다. 만약 두 개 이상의 특징점들이 근거리에 서 검출될 경우 $\min \left(\lambda_{1}, \lambda_{2}\right)$ 값이 가장 큰 블록의 중심점을 특징점으로 선택한다.

$$
\min \left(\lambda_{1}, \lambda_{2}\right)>q \lambda_{m}
$$

\section{2 변위벡터 정합}

두 영상에서 추출한 $\mathrm{KLT}$ 특징점들 간의 대응점들을 추 출하기 위하여 각 특징점을 중심으로 하는 국소영역의 텍스 처 정보를 이용한다. 국소영역의 텍스처를 기술하기 위하여 
본 논문에서는 크기 및 회전 변형에 강인한 SIFT 기술자를 적용하였다. SIFT 기술자는 특징점을 중심으로 $6 \times 16$ 크기 의 국소영역에서 그레이디언트(Gradient) 방향과 크기로 텍 스처를 표현한다[21]. 임의의 한 점 $f(x, y)$ 에 대한 방향 $\theta(x, y)$ 과 크기 $m(x, y)$ 는 다음과 같이 정의된다.

$$
\begin{aligned}
& \theta(x, y)=\tan ^{-1}\left(\frac{f(x, y+1)-f(x, y-1)}{f(x+1, y)-f(x-1, y)}\right) \\
& m(x, y)=\sqrt{\begin{array}{l}
(f(x+1, y)-f(x-1, y))^{2} \\
+(f(x, y+1)-f(x, y-1))^{2}
\end{array}}
\end{aligned}
$$

국소영역 내 각 화소의 방향에 대한 크기값을 36 개의 빈 (bin)에 누적하여 방향 히스토그램을 생성한다. 이때 가우시 안(Gaussian) 가중치 함수로 중심점에서 가까운 화소에 더 높은 가중치를 부여하고, 빈의 경계에 따른 급격한 변화를 줄이기 위해 삼선형 보간(trilinear interpolation)을 이용하여 이웃한 빈에 그 값을 배분한다. 이렇게 만들어진 방향 히스 토그램의 최대 빈이 특징점의 방향이 된다. 특징점의 방향 을 기준으로 각 화소의 그레이디언트 방향을 정규화시켜 텍 스처를 기술한다. $16 \times 16$ 크기의 국소영역을 $4 \times 4$ 크기의 부 영역으로 분할하고, 각 부영역에 나타나는 화소의 그레이디 언트 방향과 크기를 8방향 히스토그램으로 나타내면 부영역 별로 8차원의 특징 벡터가 생성된다. 따라서 특징점을 중심 으로 하는 국소영역의 텍스처는 총 128 차원의 특징벡터로 표현된다.

국소영역의 텍스처를 128 차원의 특징벡터로 기술하였으 므로, 특징벡터를 비교하여 대응되는 특징점을 찾을 수 있 다. 질의영상의 특징점 $q_{i}$ 에 대한 특징벡터를 $V_{q i}$, 참조영 상의 특징점 $r_{j}$ 에 대한 특징벡터를 $V_{r j}$ 라 할 때, 두 특징 벡터 간의 차이는 equation (7)의 유클리디안 거리로 나타 낼 수 있다.

$$
d=\left\|V_{q i}-V_{r j}\right\|=\sqrt{\sum_{k=1}^{128}\left(V_{q i}^{k}-V_{r j}^{k}\right)}
$$

유클리디안 거리를 이용하여 대응되는 특징점을 검출할 때, 두 특징점 간의 유클리디안 거리 자체보다는 거리가 가장 가까운 두 특징점 간의 거리 비율로 특징점을 대응 시키는 것이 보다 효과적이다. 특징벡터 $V_{q i}$ 에 가장 유사 한 참조영상의 특징벡터를 $V_{r j(1 s t)}$, 그다음으로 유사한 특 징벡터를 $V_{r j(2 n d)}$ 라고 할 때, 이들 특징점 간의 거리 비율 $r$ 이 임계값 $T_{r}$ 보다 작을 때 두 특징점을 대응점으로 판단 한다.

$$
r=\frac{\left\|V_{q i}-V_{r j(1 s t)}\right\|}{\left\|V_{q i}-V_{r j(2 n d)}\right\|}<T_{r}
$$

Fig. 3은 동일인으로부터 추출한 두 장문영상 간의 동인 정합(genuine match)과 타인에게서 추출한 두 장문영상 간 의 타인정합(imposter match)에서 특징점의 대응관계를 보 여주고 있다. 동인정합의 경우 대부분은 대응점의 개수가 많이 나타나고, 타인정합인 경우 대응점의 개수가 적게 나 타난다. 그렇지만 대응점의 개수만으로 두 장문영상의 유사 도를 평가한다면, Fig. $4 \mathrm{~A}$ 와 같이 동인정합에서 나타난 대 응점 개수가 Fig. $4 \mathrm{C}$ 의 타인정합에서 나타난 대응점 개수보 다 적게 나타나는 경우 오인식이 발생한다.

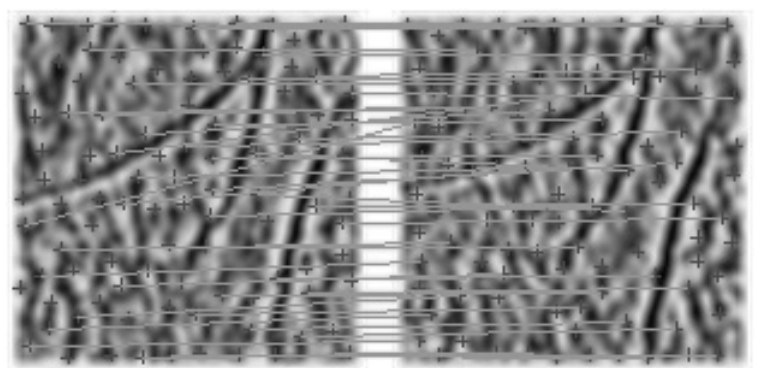

(A)

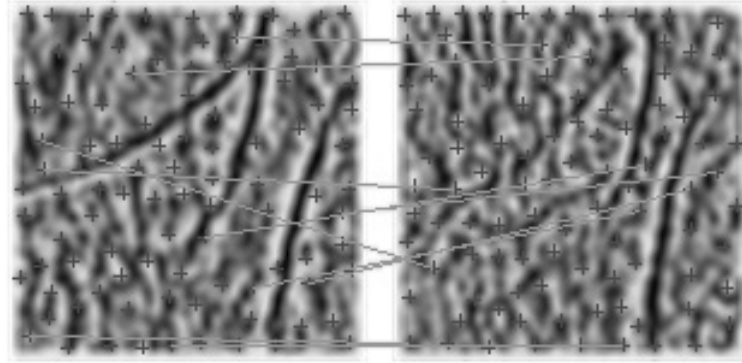

(B)

Fig. 3. Corresponding points:

(A) genuine match, (B) imposter match

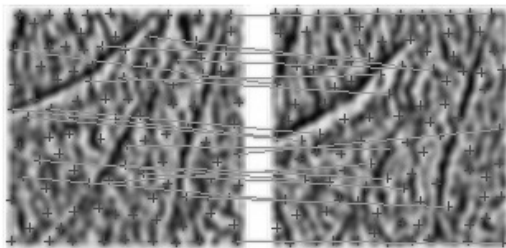

(A)

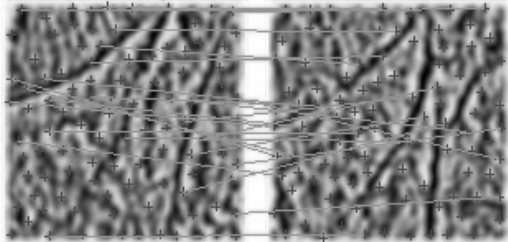

(C)

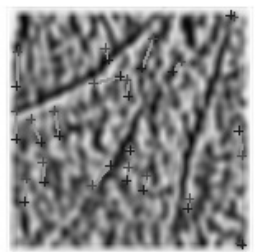

(B)

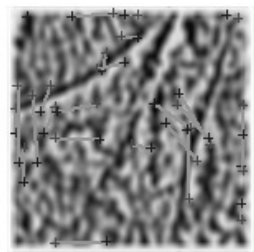

(D)
Fig. 4. Corresponding points and their displacement vectors: (A) Corresponding points of a genuine match,

(B) displacement vectors of (A), (C) corresponding points of an imposter match, (D) displacement vectors of (C) 
본 연구에서는 이러한 오인식의 문제를 해결하기 위하여 대응점 쌍으로부터 변위벡터를 생성하고, 변위벡터의 방향 과 크기에 대한 유사도를 검증하여 장문을 인식한다. 변위 벡터란 질의영상에서 추출한 특징점 $p_{1}$ 에 대응되는 참조영 상의 특징점이 $p_{2}$ 일 때, 두 점을 동일한 좌표평면에 투영시 켰을 때 두 점 간의 이동 변위를 나타내는 벡터 $\overrightarrow{p_{1} p_{2}}$ 로 정 의된다. 만약 두 개의 장문영상이 동일인으로부터 획득된 것이라면 이 두 영상 간의 변위벡터들은 유사한 크기와 방 향을 나타낼 것이고, 타인으로부터 획득된 것이라면 변위벡 터들은 상이한 크기와 방향을 갖게 될 것이다. Fig. $4 \mathrm{~B}$ 와 Fig. $4 \mathrm{D}$ 는 각각 동인정합과 타인정합에서 나타난 대응점 쌍 으로부터 생성된 변위벡터들로서, Fig. $4 \mathrm{~B}$ 에 나타난 바와 같 이 동인정합에 나타난 변위벡터들은 Fig. $4 \mathrm{D}$ 의 타인정합에 나타난 변위벡터들에 비하여 벡터들의 방향과 크기의 차이 가 크지 않음을 확인할 수 있다.

변위벡터 간의 유사도 정합을 기반으로 장문인식을 수행 하기 위해서, 두 변위벡터 $v_{1}$ 과 $v_{2}$ 의 유사도를 equation (9) 와 같이 정의하였다. $S\left(v_{1}, v_{2}\right)$ 를 두 벡터의 크기 $l_{1}, l_{2}$ 와 방 향 $o_{1}, o_{2}$ 의 차이의 곱으로 정의할 때, 두 영상 $I_{11}$ 과 $I_{2}$ 간 의 유사도 $S\left(I_{1}, I_{2}\right)$ 는 두 영상 간의 조합 가능한 변위벡터 쌍에서 벡터 간의 유사도가 임계값 $T_{s}$ 보다 큰 벡터 쌍의 개 수로 측정할 수 있다. 본 연구에서는 $\pi / n$ 간격으로 $n$ 개의 가 버 필터를 적용하므로, 질의 영상 $I_{q}$ 와 참조 영상 $I_{r}$ 간의 유 사도 $S\left(I_{q}, I_{r}\right)$ 는 식 (11)에 제시된 바와 같이 동일 방향의 가버 필터를 적용한 영상간의 유사도 평균으로 산출한다.

$$
\begin{gathered}
S\left(v_{1}, v_{2}\right)=\frac{\min \left(l_{1}, l_{2}\right)}{\max \left(l_{1}, l_{2}\right)} \times \frac{180-\left|o_{1}-o_{2}\right|}{180} \\
S\left(I_{1}, I_{2}\right)=\sum_{i=0}^{N-1} \sum_{j=i+1}^{N} F\left(V_{i}, V_{j}\right) \\
\text {, where } F\left(V_{i}, V_{j}\right)=\left\{\begin{array}{l}
1, S\left(v_{i}, v_{j}\right)>T_{s} \\
0, \text { otherwise }
\end{array}\right. \\
S\left(I_{q}, I_{r}\right)=\sum_{i=0}^{n-1} S\left(I_{q i}, I_{r i}\right) / n
\end{gathered}
$$

\section{4. 실험 결과 및 분석}

\section{1 실험 데이터}

연구 목적으로 공개된 CASIA 데이터베이스[22]를 이용하 여 제안된 방법의 성능을 실험하였다. 이 데이터베이스는 손바닥이 카메라를 향하게 하고 자연스럽게 손가락을 벌리 도록 하여 비접촉식 방식으로 촬영한 다중 스펙트럼 영상으 로, 본 연구에서는 백색광으로 촬영한 영상을 실험 데이터 로 사용하였다. 총 100 인으로부터 왼손과 오른손 각각 3장
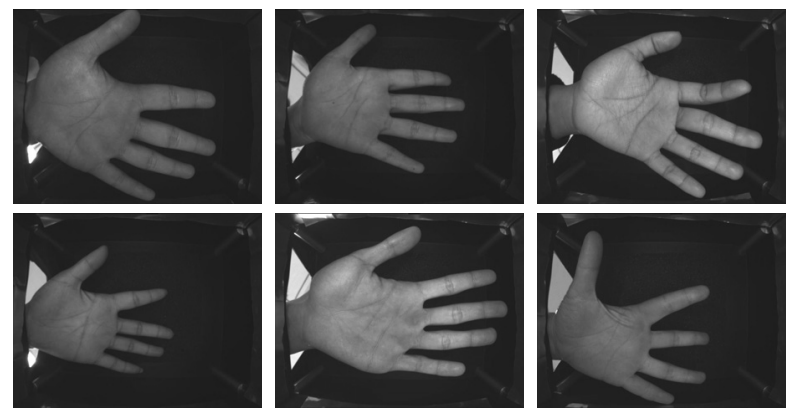

Fig. 5. Sample images of CASIA database

씩을 두 세션에 걸쳐 총 1,200 장을 촬영하였으며, 공간 해상 도는 $768 \times 596$ 이다. Fig. 5는 CASIA 데이터베이스의 일부 표본을 제시한 것으로, 손의 크기나 손가락이 벌어진 형태 가 다양하게 나타남을 알 수 있다.

\section{2 파라미터 설정}

본 논문에서 제안하는 KLT 특징점 기반의 장문인식 방 법은 두 개의 중요한 임계값 설정이 필요하다. 첫째는 $\mathrm{KLT}$ 특징점들 간의 대응점을 추출하기 위한 equation (8)의 $T_{r}$ 이다. 임계값 $T_{r}$ 이 너무 작으면 장문에 나타나는 변형에 의 하여 실제 대응점이 제대로 추출되지 않고, 너무 크면 실제 대응점이 아닌 것까지 대응점으로 추출된다. 둘째는 두 변 위벡터가 유사한지 여부를 판단하는 equation (10)의 $T_{s}$ 이 다. 임계값 $T_{s}$ 가 커질수록 두 변위벡터 간 유사성을 판정하 는 기준이 강화되어 장문의 국부적인 변형에 민감해질 수 있다.

임계값 $T_{r}$ 과 $T_{s}$ 가 인식률에 미치는 영향을 파악하고 적 절한 임계값을 찾기 위하여 첫 번째 영상을 참조영상으로 설정하고, 두 번째 세션에 수집된 왼손과 오른손 전체 영상 을 질의영상으로 사용하였다. 제안하는 시스템은 일대다 비 교에 의한 장문인식 시스템으로 정인식률 $(\mathrm{CIR}$, Correct Identification Rate)을 이용하여 성능을 측정하였다. equation (12)에서 $N$ 은 전체 인식 대상 데이터의 개수, $E$ 는 인식 오류가 발생한 개수를 나타낸다.

$$
C I R=\frac{(N-E)}{N} \times 100(\%)
$$

Fig. $6 \mathrm{~A}$ 는 KLT 특징점 간의 대응점 쌍의 개수만으로 두 장문의 유사도를 계산하여 정인식률을 구한 결과이다. 초기 임계값 $T_{r}$ 을 0.7 로 설정한 후 0.5 씩 증가시켜가면서 실험을 수행한 결과 0.9 일 때 가장 좋은 결과를 나타냈다. Fig. 6B는 $T_{r}$ 을 0.9 로 설정하여 변위벡터를 추출하고, 이들 벡터간의 유 사도를 이용하여 정인식률을 구한 결과이다. 임계값 $T_{s}$ 를 0.3 부터 0.6 까지 변화시켜가면서 실험을 수행한 결과 $T_{s}$ 가 0.5 일 때 왼손과 오른손에 관계없이 안정적인 성능을 보였으며, $T_{s}$ 에 의한 정인식률의 차이는 $1 \%$ 내외로 그다지 크지 않았다. 


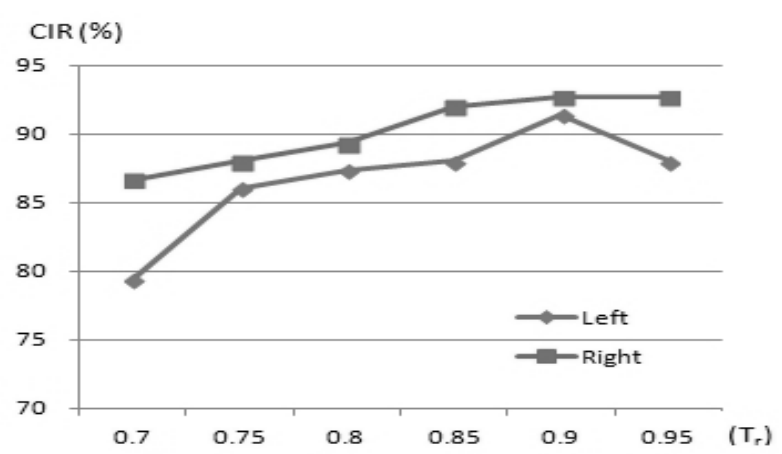

(A)

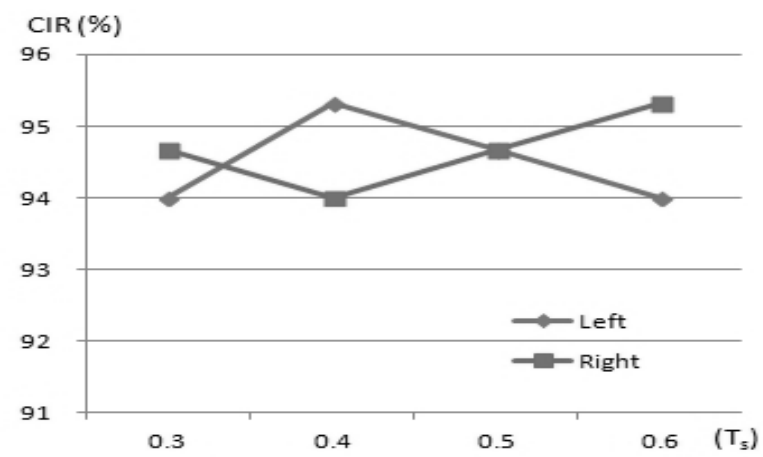

(B)

Fig. 6. CIR according to two parameters:

(A) $T_{r}$, (B) $T_{s}$

\section{3 인식 성능 측정}

생체인식 시스템이 사용되는 실제 환경과 유사한 상태로 실험을 수행하기 위하여 첫 번째 세션에 수집된 영상을 데 이터베이스에 참조영상으로 등록하고, 두 번째 세션에 수집 된 영상을 질의영상으로 사용하여 장문인식 성능을 측정하 였다. 본 연구에서는 장문에 나타나는 여러 방향의 주획과 주름을 효과적으로 기술하기 위하여, $\pi / n$ 간격으로 $n$ 개의 가버 필터를 적용하여 실험하였다. 첫 세션의 첫 번째(R1), 두 번째(R2), 세 번째(R3) 영상을 참조영상으로 하고, 둘째 세션에서 수집된 모든 영상을 질의영상으로 설정한 후 가버 필터의 개수를 변화시켜 가면서 실험한 결과 Table 1 에 제 시된 정인식률을 얻었다.

Table 1. CIR with multiple Gabor filters (\%)

\begin{tabular}{c|c|c|c|c|c}
\hline$n$ & Hand & R1 & R2 & R3 & Avg. \\
\hline \multirow{2}{*}{1} & Left & 94.7 & 96.0 & 95.3 & 95.3 \\
\cline { 2 - 6 } & Right & 94.7 & 96.7 & 96.0 & 95.8 \\
\hline \multirow{2}{*}{2} & Left & 99.3 & 99.3 & 100. & 99.6 \\
\cline { 2 - 6 } & Right & 99.3 & 97.3 & 97.3 & 98.0 \\
\hline \multirow{2}{*}{4} & Left & 98.7 & 100. & 100. & 99.6 \\
\cline { 2 - 6 } & Right & 99.3 & 98.7 & 97.3 & 98.4 \\
\hline \multirow{2}{*}{6} & Left & 98.0 & 99.3 & 100. & 99.1 \\
\cline { 2 - 6 } & Right & 100. & 98.0 & 98.0 & 98.7 \\
\hline
\end{tabular}

두 방향의 가버 필터를 적용하였을 때 단일 방향의 가 버 필터를 적용한 것에 비하여 평균 인식률을 기준으로 왼손은 $4.3 \%$, 오른손은 $2.2 \%$ 의 인식률 향상이 나타났다. 그 러나 $n$ 을 4 와 6 으로 늘렸을 경우에 인식률 향상은 그다지 크지 않았다.

제안된 방법의 성능을 기존의 방법과 비교하기 위하여 OLOF 특징을 이용한 방향코드 기반의 방법[15]과 SIFT 특징점을 이용한 텍스처 기반의 방법[17]을 직접 구현하여 성능을 측정하였다. OLOF 특징을 이용한 방향코드는 해 밍거리(Hamming distance)를 이용하여 정합을 수행한다. 이때 방향코드를 수평과 수직으로 이동시켜 비교하면 이동 변위에 위한 오차를 어느 정도 흡수할 수 있으나 처리 시 간이 이동거리의 제곱에 비례하여 늘어나게 된다. 본 실험 에서는 이동거리를 \pm 10 으로 설정하였다. SIFT 특징점을 이용한 방법은 equation (8)의 임계값 $T_{r}$ 이 성능에 영향을 미치는 중요한 파라미터이다. SIFT 기술자를 이용하기 때 문에 제안된 방법과 동일하게 $T_{r}$ 을 0.9 로 설정하여 실험하 였다. 실험 결과 Table 2에 나타난 바와 같이 제안된 방법 이 OLOF와 SIFT를 이용한 방법에 비하여 더 높은 정인식 률을 보였다.

Table 2. Performance comparison by CIR (\%)

\begin{tabular}{c|c|c|c|c|c}
\hline Method & Hand & R1 & R2 & R3 & Avg. \\
\hline \multirow{2}{*}{ OLOF[15] } & Left & 92.7 & 98.0 & 93.3 & 94.7 \\
\cline { 2 - 6 } & Right & 94.0 & 94.7 & 94.7 & 94.4 \\
\hline \multirow{2}{*}{ SIFT[17] } & Left & 94.7 & 95.3 & 94.0 & 94.7 \\
\cline { 2 - 6 } & Right & 92.7 & 93.3 & 90.0 & 92.0 \\
\hline \multirow{2}{*}{$\begin{array}{c}\text { Proposed } \\
(n=2)\end{array}$} & Left & 99.3 & 99.3 & 100. & 99.6 \\
\cline { 2 - 6 } & Right & 99.3 & 97.3 & 97.3 & 98.0 \\
\hline
\end{tabular}

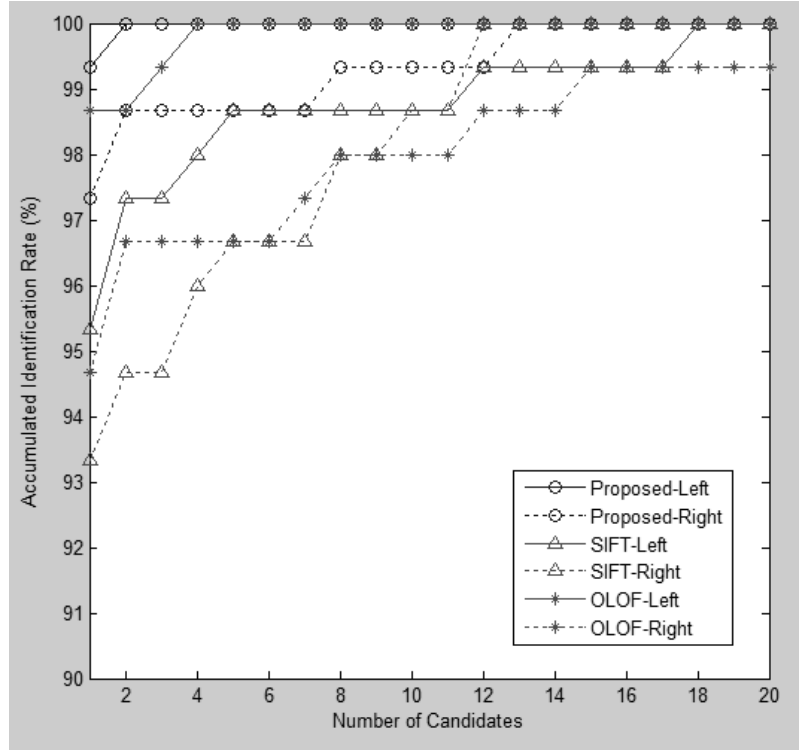

Fig. 7 Performance comparison by accumulated identification rate 
Fig. 7은 Table 2의 R2, 즉 두 번째 영상을 참조영상으 로 하였을 때, 인식 대상 후보의 개수를 20개까지 늘려가면 서 누적된 인식률을 도시한 것이다. 누적 인식률에서도 제 안된 방법이 효과적임을 확인할 수 있었으며, 사용된 인식 방법에 무관하게 왼손이 오른손에 비하여 더 정확하게 인 식되었다.

\section{5. 결 론}

카메라를 이용하여 일정 거리에서 자연스럽게 장문을 획 득할 수 있고, 접촉식에서 발생하는 위생상의 문제를 해결 할 수 있기 때문에 최근 비접촉 장문인식에 대한 연구가 관 심을 끌고 있다. 그러나 비접촉 장문은 상대적으로 크기 및 회전 변형이 크게 발생한다. 이러한 문제를 해결하기 위하 여 손의 크기와 방향을 고려하여 관심영역 $(\mathrm{ROI})$ 을 추출한 후 정규화함으로써 크기 및 회전 변형을 최소화하였다. 본 논문에서는 안정적이고 신속하게 검출이 가능한 $\mathrm{KLT}$ 특징 점을 기반으로, 대응점 쌍으로부터 정의되는 변위벡터들 간 의 유사도를 측정하는 비접촉 장문인식 방법을 제안하였다. 제안된 방법은 기존의 $\mathrm{OLOF}$ 특징을 이용한 방향코드와 SIFT 특징점을 이용한 방법에 비하여 보다 우수한 성능을 나타내었다. 특히 여러 방향의 가버 필터를 이용할 경우 99\%를 상회하는 정인식률을 얻을 수 있었다.

\section{References}

[1] D. Zhang, W. Kong, J. You, and M. Wong, "Online palmprint identification," IEEE Trans. on Pattern Analysis and Machine Intelligence, Vol.25, No.9, pp.1041-1050, 2003.

[2] K. Shin, K. Rhee, "Palmprint identification algorithm using $\mathrm{Hu}$ invariant moments," Journal of the Institute of Electronics Engineers of Korea, Vol.42, No.2, pp.31-38, 2005.

[3] G. K. Michael, T. Connie, and A. B. Teoh, "Touch-less palm print biometrics: Novel design and implementation," Image and Vision Computing, Vol.26, pp.1551-1560, 2008.

[4] A. Kong, D. Zhang, and M. Kamel, "A survey of palmprint recognition," Pattern Recognition, Vol.42, pp.1408-1418, 2009.

[5] M. Ekinici, M. Aykut, "Gabor-based kernel PCA for palmprint recognition," Electronics Letters, Vol.43, No.20, pp.1077-107 -110, 2004.

[6] Chinese Academy of Sciences' Institute of Automation (CASIA) Multi-spectral Palmprint Database. http:// biometrics.idealtest.org
[7] X. Wu, D. Zhang, and K. Wang, "Palm line extraction and matching for personal authentication," IEEE Trans. on System, Man, and Cybernetics, Vol.36, No.5, pp.978-987, 2006.

[8] L. Liu, D. Zhang, "A novel palm-line detector," Lecture Notes in Computer Science, Vol.3546, pp.563-571, 2005.

[9] D. Huang, W. Jia, and D. Zhang, "Palmprint verification based on principal lines," Pattern Recognition, Vol.41, No.4, pp.1316-1328, 2008.

[10] A. W. Kong, D. Zhang, "Competitive coding scheme for palmprint verification," Proc. of the 17th International Conference on Pattern Recognition, pp.520-523, 2004.

[11] X. Wu. K. Wang, and D. Zhang, "Palmprint authentification based on orientation code matching," Lecture Notes in Computer Science, Vol.3546, pp.555-562, 2005.

[12] F. Yue, W. Zuo, D. Zhang, and K. Wang, "Orientation selection using modified FCM for competitive code-based palmprint recognition," Pattern Recognition, Vol.42, pp. 2841-2849, 2009.

[13] W. Jia, D. Huang, and D. Zhang, "Palmprint verification based on robust line orientation code," Pattern Recognition, Vol.41, pp.1504-1513, 2008.

[14] M. Kim, "Palmprint recognition based on line and slope orientation features," Journal of Information Science and Engineering, Vol.27, pp.1219-1232, 2011.

[15] Z. Sun, T. Tan, Y. and Wang, Z. Li, "Ordinal palmprint representation for personal identification," Proc. of the IEEE Computer Society Conf. on Computer Vision and Pattern Recognition, Vol.1, pp.279-284, 2005.

[16] G. Michael, T. Connie, and A. Teoh, "Touch-less palm print biometrics: Novel design and implementation," Image and Vision Computing, Vol.26, pp.1551-1560, 2008.

[17] A. Morales, M. A. Ferrer, and A. Kumar, "Towards contactless palmprint authentication," IET Computer Vision, Vol.5, No.6, pp.407-416, 2011.

[18] Y. Yang, Q. Ruan, and X. Pan, "An improved square-based palmprint segmentation method," Proc. of the International Symposium on Intelligent Signal Processing and Communication Systems, pp.316-310, 2007.

[19] A. Kumar, D. Zhang, "Personal recognition using hand shape and texture," IEEE Trans. on Image Processing, Vol. 15, No.8, pp.2454-2461, 2006.

[20] J. Shi, C. Tomasi, "Good features to track," Proc. of the IEEE Computer Society Conference on Computer Vision and Pattern Recognition, pp.593-600, 1994.

[21] D. G. Lowe, "Distinctive image features from scale-invariant keypoints," Internationial Journal of Computer Vision, Vol. 60, No.2, pp.91-110, 2004.

[22] Chinese Academy of Sciences' Institute of Automation (CASIA) Multi-spectral Palmprint Database. http:// biometrics.idealtest.org 


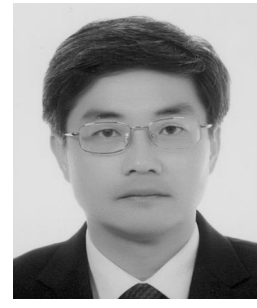

\section{김 민 기}

e-mail:mkkim@gnu.ac.kr

1989년 중앙대학교 전자계산학과(이학사)

1994년 중앙대학교 전자계산학과(이학석사)

1998년 중앙대학교 컴퓨터공학과(공학박사)

1998년 1999년 KRIC 선임연구원

1999년 2000년 KERIS 책임연구원, 연구위원

2000년 2010년 경상대학교 컴퓨터교육과 부교수

2011년 현 재 경상대학교 컴퓨터과학과 교수

2013년 2014년 미국 University of Notre Dame 방문학자

2014년 현 재 경상대학교 공학연구원 자동화 - 컴퓨터연구센터 연구원

관심분야: Biometrics, Pattern Recognition, Image Processing 